\title{
Early neonatal morbidities and neurological functioning of preterm infants 2 weeks after birth
}

\author{
Maaike A. Hempenius ${ }^{1} \cdot$ Elise A. Verhagen ${ }^{1} \cdot$ Jozien C. Tanis ${ }^{1} \cdot$ Christa Einspieler $^{2} \cdot$ Arend F. Bos $^{1}$
}

Received: 29 January 2018 / Accepted: 2 August 2018 / Published online: 3 September 2018

(c) Springer Nature America, Inc. 2018

\begin{abstract}
Objective To determine the association between potential neonatal risk factors and the quality of general movements (GMs) in preterm infants.

Study design Prospective cohort study in 67 preterm infants. From video recordings made on Days 8 and 15, we scored the GMs as normal/abnormal and detailed aspects using the general movement optimality score (GMOS). Risk factors included respiratory insufficiency requiring mechanical ventilation, patent ductus arteriosus (PDA), and abnormal blood glucose levels. We used multiple regression analyses.

Result On Day 8 after birth, the presence of a PDA remained in the multivariable model, explaining $17.1 \%$ of the variance in GMOS (beta, - 0.414). On Day 15, duration of mechanical ventilation and frequency of hypoglycemic episodes explained $38.8 \%$ of the variance (betas, -0.382 and -0.466 , respectively).

Conclusion In preterm infants, PDA, duration of mechanical ventilation, and frequency of hypoglycemic episodes were associated with poorer neurological functioning during the first 2 weeks after birth.
\end{abstract}

\section{Introduction}

Preterm neonatal survival rates have increased considerably during the past decades due to improved neonatal intensive care and improved therapy [1]. These improvements are, however, accompanied by a higher prevalence of neurodevelopmental sequelae [2-4]. Studies have shown that children born very preterm, i.e., gestational age $(\mathrm{GA}) \leq$ 32 weeks and with a very low birth weight (BW) $(\leq 1500$ $\mathrm{g})$, are at an increased risk of poorer motor skills, poorer performance on several neuropsychological domains, and behavioral problems $[5,6]$.

It continues to be a challenge for clinicians to identify which preterm infants are at increased risk of subsequent neurodevelopmental deficits. Some risk factors for

Maaike A. Hempenius

m.a.hempenius@umcg.nl

1 Division of Neonatology, Beatrix Children's Hospital, University Medical Center Groningen, University of Groningen, Groningen, The Netherlands

2 Interdisciplinary Developmental Neuroscience, Department of Phoniatrics, Medical University of Graz, Graz, Austria neurodevelopmental sequelae are well known, but for some other potential risk factors it is unclear whether they do indeed increase the risk of neurodevelopmental sequelae. These risks include three clinical problems that occur early in the neonatal period, i.e., respiratory insufficiency requiring mechanical ventilation [7-9], patent ductus arteriosus (PDA) [10, 11], and disturbances in glucose homeostasis [12-15]. As yet, contradictory findings are reported on the association between these risk factors and neurodevelopmental outcome. To our knowledge, the relation between these risks and neurological findings as early as during the neonatal period have not been investigated.

The best way to investigate neurological functioning during the neonatal period in the individual infant is the assessment of general movements (GMs) according to Prechtl [16-18]. This is a sensitive, non-invasive method to assess the integrity of the brain at an early age [18-20]. GMs are spontaneous movements that start during fetal life and continue until four to 5 months post term [19]. Normal GMs are characterized by complexity and variability, and reflect normal neurological development $[18,19]$. The quality of GMs from the second week after birth is an indicator of brain dysfunction and is a strong predictor of mild neurological and motor disorders [20-24] and intelligence [20, 24]. By adding the assessment of detailed aspects of the GMs, a general 
movement optimality score (GMOS) can be calculated [25]. A detailed scoring increases the accuracy of the general movement assessment (GMA) by providing a score for the degree of brain dysfunction [21-26].

Using GMA, including the detailed scoring of the GMs' optimality (by means of the GMOS), it may be possible to determine whether several neonatal morbidities are indeed associated with impaired neurological functioning. The GMA and GMOS can be applied during or very soon after these morbidities, contributing to our understanding whether these morbidities are indeed risk factors for poorer neurological functioning. The aim of our study was, therefore, to investigate whether three common clinical problems of preterm infants, which potentially increase the risk of neurodevelopmental sequelae, i.e., mechanical ventilation, PDA, and disturbances in glucose homeostasis, are associated with neurological functioning during the neonatal period.

\section{Methods}

\section{Patients}

We performed an observational cohort study on 67 preterm infants born before or at 32 weeks' gestation at University Medical Center Groningen (UMCG), a tertiary care center in Groningen, the Netherlands. The median GA was 30.1 weeks. All infants were admitted to the Neonatal Intensive Care Unit (NICU) of the Beatrix Children's Hospital of UMCG between May 2006 and October 2007 and between June 2012 and April 2013, and were part of two studies [21, 27]. Exclusion criteria were congential malformations and chromosomal abnormalities. Patient characteristics are listed in Table 1. All parents gave their written informed consent on behalf of their children for using the clinical data and for the making of the video recordings. The Ethical Review Board of UMCG approved the study.

\section{Recordings}

Video recordings, of at least $45 \mathrm{~min}$, were prospectively made of the infants on Days 8 and 15 after birth, with the infant lying supine in the incubator and wearing only a nappy. The camera was placed at the foot of the incubator and high enough to obtain an unobstructed view of the infant's entire body. GMs during crying, hiccupping, or while the infant was sucking on a dummy were excluded from the analyses [19].

\section{Movement optimality on Days 8 and 15}

To score the GMs we used the GMA according to Prechtl $[16,19,28]$ supplemented with a detailed score of
Table 1 Characteristics of the study group $(N=67)$

\begin{tabular}{ll}
\hline Clinical characteristics & $n(\%)$ or median (range) \\
\hline Male/female & $30 / 37(45 / 55)$ \\
Gestational age in weeks, median & $30.1(26.0-32.1)$ \\
(range) & $1200(560-2250)$ \\
Birth weight in grams, median (range) & $-0.51(-2.43-2.10)$ \\
Birth weight $z$-score ${ }^{a}$, median (range) & $21(31)$ \\
Small-for-gestational age & \\
Cerebral pathology & $25(37)$ \\
No abnormalities & $40(60)$ \\
PVE & $10(15)$ \\
Mild GMH (grades 1 and 2) & $2(3)$ \\
Severe GMH (grade 3 and PVHI) & $1(2)$ \\
PVL &
\end{tabular}

$P V E$ periventricular echodensities, GMH germinal matrix hemorrhage, $P V H I$ periventricular hemorrhagic infarction, $P V L$ periventricular leukomalacia

${ }^{a} z$-score according to Kloosterman [29]

qualitative aspects of the GMs [25]. Scoring involved two separate steps. First, we scored the GMs globally, classifying them into four categories, i.e., normal, poor repertoire, cramped-synchronized, and chaotic GMs [19]. Second, we calculated the GMOS on the basis of detailed qualitative characteristics of the GMs. The qualitative characteristics we assessed were the four global GM categories, supplemented with amplitude, speed, spatial range, proximal and distal rotations, onset and offset, tremulous movements, and cramped components focusing separately on the trunk, neck, and upper and lower limbs [25]. The GMOS given in this way ranges from 5 (low optimality) to 42 (high optimality) [25]. Einspieler et al. [25] reported a good interobserver agreement for this detailed assessment (Cohen's kappa 0.69-0.82).

Each recording was scored by MAH and AFB. The observers were unaware of the infants' clinical history and their neurological outcomes. If GMs were absent or very short (less than $3 \mathrm{~s}$ ) during the 45-minute recording, the infant was scored as hypokinetic, and no detailed score was given.

\section{Neonatal morbidities}

\section{Ventilation}

We collected data about respiratory insufficiency requiring ventilatory support, including type (mechanical ventilation, CPAP, high flow, low flow) and the duration of mechanical ventilation, in days until the time of recording on Days 8 and 15 . In our standard of care, infants who receive ventilator support are not routinely sedated. Treatment with 
caffeine was also recorded. For this study, we focused on whether infants were intubated and mechanically ventilated, and on the duration of mechanical ventilation.

\section{Patent ductus arteriosus}

Starting from Day 2 onwards, we considered the presence of patency of the ductus arteriosus on clinical grounds and, if necessary, we performed echocardiography. We scored a PDA as present if a hemodynamically significant left-toright shunt that, according to the team of neonatologist and cardiologists, required treatment, i.e., a symptomatic PDA, was present. If left-to-right shunting through the PDA was small and not hemodynamically significant, we scored the PDA as absent.

\section{Glucose homeostasis}

Blood glucose was measured with i-STAT System ${ }^{\circledR}$ (pointof-care measurement, Abbott Point of Care Inc., Princeton, $\mathrm{NJ})$ at 3, 6, 9, 12, 18, 24, and $48 \mathrm{~h}$ after birth. Mean blood glucose was calculated for the first day. Hypoglycemia was defined as blood glucose $<2.6 \mathrm{mmol} / \mathrm{L}(46 \mathrm{mg} / \mathrm{dL})$ and hyperglycemia $>10.0 \mathrm{mmol} / \mathrm{L}(180 \mathrm{mg} / \mathrm{dL})$. We also calculated the number of hypoglycemic and hyperglycemic episodes per infant.

\section{Data analyses and statistics}

We used descriptive statistics summarizing continuous variables as median and range. For categorical data we presented numbers and percentages. Next, we performed univariable linear regression analyses to determine which characteristics of the infants were related to the GMOS on Day 8 and on Day 15. In all analyses the conditions required for linear regression analyses were met, that is the distribution of the residuals were normally distributed. The variables we included as predictors for the GMOS were yes/no mechanical ventilation, the duration of mechanical ventilation in days until the time of recording, yes/no PDA, mean blood glucose concentration during the first $24 \mathrm{~h}$, and frequency of hypoglycemic and hyperglycemic episodes during the first $48 \mathrm{~h}$. To test for possible confounders we also performed univariable linear regression analyses with the variables GA, BW $z$-score using the Dutch Kloosterman curve [29], grading of germinal matrix hemorrhage (GMH), and yes/no periventricular echodensities (PVE).

Subsequently, we used backward multiple linear regression analyses to determine which variables that had been detected by the univariable analyses with $P<0.15$, were independently associated with GMOS on Day 8 and Day 15. We used IBM SPSS Statistics for Windows, Version
23.0 (IBM Corp., Armonk, USA) for the statistical analyses. $P<0.05$ was considered significant.

\section{Results}

\section{Mechanical ventilation, PDA, and glucose homeostasis}

We present the clinical data of the infants in Table 2. Fortyfour $(66 \%)$ out of the 67 infants received mechanical ventilation during the study period. The median duration was 2 days (range, $2.5 \mathrm{~h}-8$ days) during the first 8 days and also 2 days ( $2.5 \mathrm{~h}-15$ days) during the first 15 days. On Day 15 , eleven $(17 \%)$ out of the 64 infants were mechanically

Table 2 Prevalence of mechanical ventilation, PDA, and disturbances in glucose homeostasis during the neonatal period in preterm infants

\begin{tabular}{|c|c|}
\hline Clinical problems & $n(\%)$ or median (range) \\
\hline \multicolumn{2}{|l|}{ Mechanical ventilation $^{a}$} \\
\hline Mechanical ventilation & $44(66)$ \\
\hline $\begin{array}{l}\text { Receiving mechanical ventilation on Day } \\
8\end{array}$ & $11(16)$ \\
\hline $\begin{array}{l}\text { Duration of mechanical ventilation until } \\
\text { Day } 8\end{array}$ & 2 days ( $2.5 \mathrm{~h}-8$ days) \\
\hline $\begin{array}{l}\text { Receiving mechanical ventilation on Day } \\
15\end{array}$ & $11(17)$ \\
\hline $\begin{array}{l}\text { Duration of mechanical ventilation until } \\
\text { Day } 15\end{array}$ & 2 days ( $2.5 \mathrm{~h}-15$ days) \\
\hline \multicolumn{2}{|l|}{ PDA } \\
\hline PDA & $27(40)$ \\
\hline No treatment & $3(4)$ \\
\hline Indomethacin or ibuprofen treatment & $24(36)$ \\
\hline Ductus clipping & $4(6)$ \\
\hline Day of ductus clipping, median (range) & $26(20-41)$ \\
\hline \multicolumn{2}{|l|}{ Glucose levels during the first $48 \mathrm{~h}^{\mathrm{b}}$} \\
\hline Mean blood glucose (mmol/L) & $4.3(2.7-12.9)$ \\
\hline Severe hypoglycemia $<1.7 \mathrm{mmol} / \mathrm{L}$ & $4(6)$ \\
\hline Hypoglycemic episode $(\mathrm{s})<2.6 \mathrm{mmol} / \mathrm{L}^{\mathrm{b}}$ & $16(24)$ \\
\hline Once & $6(9)$ \\
\hline Twice & $9(14)$ \\
\hline Three times, or more & $1(2)$ \\
\hline Hyperglycemic episode $(\mathrm{s})>10.0 \mathrm{mmol} / \mathrm{L}^{\mathrm{b}}$ & $3(4)$ \\
\hline Once & $1(2)$ \\
\hline Twice & $1(2)$ \\
\hline Tree times, or more & $1(2)$ \\
\hline
\end{tabular}

$P D A$ patent ductus arteriosus

${ }^{a}$ Defined as synchronized intermittent positive pressure ventilation, synchronized intermittent mandatory ventilation, and/or highfrequency oscillatory ventilation

${ }^{\mathrm{b}}$ Blood glucose was measured at 3, 6, 9, 12, 18, 24, and $48 \mathrm{~h}$ after birth 
ventilated, of whom four continuously during the 15 days. Twenty-seven (40\%) infants had a PDA, of whom 24 were symptomatic. They were treated with indomethacin or ibuprofen. Four of these infants were treated surgically after the age of 2 weeks. Sixteen (24\%) infants had hypoglycemia a least once, while hyperglycemia occurred rarely.

Of the 67 infants, 19 had none of these clinical conditions, whereas six infants had all three conditions.

\section{Video recordings}

On Day 8 , we missed the video recordings of four infants $(6 \%)$, and seven infants $(10 \%)$ were scored as hypokinetic due to sepsis, making the total amount of infants assessed by GMOS $n=56(84 \%)$. Three infants passed away between the age of eight and 15 days. On Day 15, we missed 24 recordings $(36 \%)$ and three infants $(4 \%)$ were scored hypokinetic, again due to sepsis. We could not assess one infant's GMOS due to his clothing, making the total amount of assessed infants $n=37$ (55\%).

\section{Quality of general movements}

The number of infants with normal and abnormal GMs during the two periods and the scores of the GMOS are displayed in Table 3. Eleven infants (20\%) had normal GMs on Day 8 and $45(80 \%)$ had poor repertoire GMs. None of the infants had cramped-synchronized and/or chaotic GMs. The median GMOS on Day 8 was 27 (percentile 25-75, 23-34).

On Day 15, 12 infants (32\%) were scored as having normal GMs and $25(68 \%)$ as having poor repertoire GMs. None of the infants had cramped-synchronized and/or chaotic GMs. The median GMOS on Day 15 was 32 (29-39).

Table 3 The quality of general movements and optimality scores

\begin{tabular}{lll}
\hline & $\begin{array}{l}\text { Day 8, } n(\%), \\
n=56\end{array}$ & $\begin{array}{l}\text { Day 15, } n(\%), \\
n=37\end{array}$ \\
\hline $\begin{array}{l}\text { Quality of GMs } \\
\text { Normal GMs }\end{array}$ & $11(20)$ & $12(32)$ \\
$\quad$ Poor repertoire & $45(80)$ & $25(68)$ \\
$\quad$ Chaotic & $0(0)$ & $0(0)$ \\
$\quad$ Cramped-synchronized & $0(0)$ & $0(0)$ \\
Motor optimality scores & & $32(29-39)^{\mathrm{a}}$ \\
$\quad$ GMOS, median & $27(23-34)$ & \\
$\quad$ P25-75) & & $3(4)$ \\
Not assessable & $7(10)$ & $24(36)$ \\
Hypokinetic & $4(6)$ & $3(4)$ \\
No recording & $0(0)$ & \\
Passed away &
\end{tabular}

${ }^{\mathrm{a}}$ One infant with normal GMs was not assessable for the GMOS on Day 15 due to its clothing

\section{Relation between early clinical problems and quality of GMs using multivariable analyses}

To determine which characteristics of the infants were related to the GMOS, we entered mechanical ventilation, the duration of mechanical ventilation, PDA, mean blood glucose concentration, and the frequency of hypoglycemia and hyperglycemia into the univariable linear regression analyses. As possible confounders we considered GA, BW $z$-score, GMH, and PVE. We present the results of these analyses in Table 4a for Day 8 and in Table 4b for Day 15.

On Day 8, GMH, GA, mechanical ventilation, duration of mechanical ventilation, and PDA were associated with GMOS with $P<0.15$. We used these variables for the construction of several backward multivariable linear regression models to test which predictors contributed independently to the GMOS on Day 8, adjusted for potential confounders. In Table 5a we present two different models. GMH and GA were entered as confounders. Since mechanical ventilation correlated strongly with duration of mechanical ventilation we entered them into different models to avoid interaction. The first model, therefore, included mechanical ventilation, PDA, GMH, and GA. PDA remained in the model with $P=0.002$. The second model included duration of mechanical ventilation, PDA, GMH, and GA. Again, only PDA remained in the model with $P=0.002$, explaining $17.1 \%$ of the variance of the GMOS on Day 8.

On Day 15, GA, mechanical ventilation, duration of mechanical ventilation, and frequency of hypoglycemia and hyperglycemia were associated with GMOS with $P<$ 0.15 . We present the results in Table 4b. Again, we constructed several multivariable linear regression models to test which variables contributed independently to the GMOS. We present the models in Table 5b. Only GA was entered as a potential confounder. Because mechanical ventilation correlated strongly with duration of mechanical ventilation, we constructed two models to test which of the two variables contributed most to the GMOS. The models included GA and frequency of hypoglycemia, and either mechanical ventilation or duration of mechanical ventilation. In the two models, both mechanical ventilation and duration of mechanical ventilation were significant predictors, with $P=0.036$ and $P=0.008$, respectively. Because duration of mechanical ventilation had the strongest contribution to the model, we used this variable to construct the final model. In this model, we also included the frequency of hyperglycemia, the frequency of hypoglycemia, and the duration of mechanical ventilation in days until Day 15. Duration of mechanical ventilation and the frequency of hypoglycemia remained in this model, together explaining $38.8 \%$ of the variance of the GMOS on Day 15. 
Table 4a Relation between the risk factors and GMOS using univariable linear regression analyses in preterm infants on Day 8

Table 4b Relation between the risk factors and GMOS using univariable linear regression analyses in preterm infants on Day 15

\begin{tabular}{|c|c|c|c|c|c|}
\hline Variable & $R^{2}$ & $B$ & $95 \%$ CI for $B$ & Beta & $P$-value \\
\hline GA & 0.155 & 1.62 & 0.59 to 2.65 & 0.393 & 0.003 \\
\hline BW $z$-score ${ }^{\mathrm{a}}$ & 0.022 & 0.92 & -0.14 to 2.57 & 0.149 & 0.273 \\
\hline GMH & 0.067 & -3.21 & -6.49 to 0.07 & -0.258 & 0.055 \\
\hline $\mathrm{PVE}^{\mathrm{b}}$ & 0.010 & 1.27 & -2.45 to 4.98 & 0.101 & 0.496 \\
\hline Mechanical ventilation & 0.067 & -3.40 & -6.85 to 0.05 & -0.260 & 0.053 \\
\hline Duration of ventilation & 0.069 & -0.75 & -1.50 to 0.004 & -0.262 & 0.051 \\
\hline PDA & 0.171 & -5.48 & -8.77 to -2.19 & -0.414 & 0.002 \\
\hline Mean glucose & 0.025 & -0.58 & -1.56 to 0.40 & -0.159 & 0.241 \\
\hline Frequency hypoglycemia & 0.010 & 0.71 & -1.25 to 2.68 & 0.098 & 0.470 \\
\hline Frequency hyperglycemia & $<0.001$ & 0.09 & -2.77 to 2.94 & 0.008 & 0.952 \\
\hline
\end{tabular}

${ }^{a} z$-score according to Kloosterman [29]

${ }^{\mathrm{b}} \mathrm{GMH}$ was excluded for the analysis of PVE

\begin{tabular}{llllll}
\hline Variable & $R^{2}$ & $B$ & $95 \%$ CI for $B$ & Beta & $P$-value \\
\hline GA & 0.092 & 1.21 & -0.12 to 2.54 & 0.303 & $\mathbf{0 . 0 7 3}$ \\
BW z-score & & & \\
GMH & 0.001 & 0.19 & -1.88 to 2.25 & 0.031 & 0.857 \\
PVE $^{\text {b }}$ & 0.008 & 0.76 & -2.13 to 3.66 & 0.091 & 0.596 \\
Mechanical ventilation & 0.058 & -2.60 & -6.66 to 1.46 & -0.241 & 0.200 \\
Duration of ventilation & 0.112 & -3.59 & -7.12 to -0.06 & -0.334 & $\mathbf{0 . 0 4 7}$ \\
PDA & 0.172 & -0.72 & -1.28 to -0.17 & -0.415 & $\mathbf{0 . 0 1 2}$ \\
Mean glucose & 0.023 & -1.79 & -5.90 to 2.31 & -0.150 & 0.381 \\
Frequency hypoglycemia & 0.243 & -3.47 & -5.60 to -1.33 & -0.493 & $\mathbf{0 . 0 0 2}$ \\
Frequency hyperglycemia & 0.232 & -7.81 & -12.78 to -2.85 & -0.481 & $\mathbf{0 . 0 0 3}$ \\
\hline
\end{tabular}

${ }^{a} z$-score according to Kloosterman [29]

${ }^{\mathrm{b}} \mathrm{GMH}$ was excluded for the analysis of PVE

\begin{tabular}{llllll}
\hline Variable & $R^{2}$ & $B$ & $95 \%$ CI for $B$ & Beta & $P$-value \\
\hline $\begin{array}{lllll}\text { MODEL 1a } \\
\quad\end{array}$ & & & & \\
Mechanical ventilation & $0.243^{\mathrm{a}}$ & -0.47 & -4.26 to 3.32 & -0.036 & 0.805 \\
GMH & $0.242^{\mathrm{a}}$ & -2.20 & -5.34 to 0.95 & -0.176 & 0.167 \\
GA & $0.214^{\mathrm{a}}$ & 1.00 & -0.19 to 2.18 & 0.242 & 0.097 \\
PDA & 0.171 & -5.48 & -8.77 to -2.19 & -0.414 & 0.002 \\
MODEL 1b & & & & & \\
Duration of ventilation & $0.243^{\mathrm{a}}$ & -0.076 & -0.92 to 0.77 & -0.027 & 0.857 \\
GMH & $0.242^{\mathrm{a}}$ & -2.20 & -5.34 to 0.95 & -0.176 & 0.167 \\
GA & $0.214^{\mathrm{a}}$ & 1.00 & -0.19 to 2.18 & 0.242 & 0.097 \\
PDA & 0.171 & -5.48 & -8.77 to -2.19 & -0.414 & $\mathbf{0 . 0 0 2}$ \\
\hline
\end{tabular}

Table 5a Relation between the risk factors and GMOS using multiple linear regression in preterm infants on Day 8
$P<0.05$ was considered significant.

${ }^{a}$ The reported $R^{2}$ values represent those of the entire model. They are recalculated each time a factor is removed from the model. Thus, for model 1, mechanical ventilation, GMH, GA, and PDA together explained $24.3 \%$ of the variance, whereas GMH, GA, and PDA together explained $24.2 \%$ of the variance, and GA and PDA together $21.4 \%$ of the variance 
Table 5b Relation between the risk factors and GMOS using multiple linear regression in preterm infants on Day 15

\begin{tabular}{llllll}
\hline Variable & $R^{2}$ & $B$ & $95 \%$ CI for $B$ & Beta & $P$-value \\
\hline $\begin{array}{lllll}\text { MODEL 1a } \\
\quad \text { GA }\end{array}$ & $0.379^{\mathrm{a}}$ & 0.86 & -0.36 to 2.07 & 0.214 & 0.161 \\
$\quad$ Mechanical ventilation & 0.339 & -3.34 & -6.43 to -0.240 & -0.311 & $\mathbf{0 . 0 3 6}$ \\
$\quad$ Frequency hypoglycemia & 0.339 & -3.36 & -5.39 to -1.33 & -0.478 & $\mathbf{0 . 0 0 2}$ \\
MODEL 1b & & & & & \\
$\quad$ GA & $0.402^{\mathrm{a}}$ & 0.55 & -0.76 to 1.85 & 0.136 & 0.401 \\
$\quad$ Duration of ventilation & 0.388 & -0.67 & -1.15 to -0.18 & -0.382 & $\mathbf{0 . 0 0 8}$ \\
$\quad$ Frequency hypoglycemia & 0.388 & -3.28 & -5.23 to -1.32 & -0.466 & $\mathbf{0 . 0 0 2}$ \\
MODEL 2 & & & & & \\
$\quad$ Frequency hyperglycemia & $0.444^{\mathrm{a}}$ & -4.25 & -9.08 to 0.58 & -0.262 & 0.083 \\
$\quad \begin{array}{l}\text { Duration of ventilation } \\
\text { Frequency hypoglycemia }\end{array}$ & 0.388 & -0.67 & -1.15 to -0.18 & -0.382 & $\mathbf{0 . 0 0 8}$ \\
\hline
\end{tabular}

$P<0.05$ was considered significant.

aThe reported $R^{2}$ values represent those of the entire model. They are recalculated each time a factor is removed from the model

\section{Discussion}

This study demonstrated that several neonatal factors were associated with brain functioning during the first 2 weeks after birth, as measured by a detailed score reflecting the individual optimality of the quality of GMs. The presence of a PDA was associated with poorer neurological functioning on Day 8, while the duration of mechanical ventilation and the frequency of hypoglycemic episodes were associated with poorer neurological functioning on Day 15. This suggests that these three risk factors might be involved in impaired neurological and developmental outcomes later on.

The strongest association we found concerned the frequency of hypoglycemic episodes during the first 2 days after birth and impaired neurological functioning on Day 15. Surprisingly, we did not find this association on Day 8 . The reason might be that the association between glucose homeostasis and neurological functioning on Day 8 was not significant because the presence of a PDA is a greater hazard at that age. Consensus is lacking among pediatricians on the absolute threshold values for hypoglycemia that leads to brain injury [30]. Lucas et al. [13] reported that in preterm infants weighing less than $1850 \mathrm{~g}$ at birth, blood glucose concentrations below $2.5 \mathrm{mmol} / \mathrm{L}(45 \mathrm{mg} / \mathrm{dL})$ during the first 10 days offer the greatest power to predict reduced mental and motor development scores at 18 months. Tin et al. [14] failed to replicate these findings. They suggested that the critical threshold for blood glucose concentration should be lower than many pediatricians had been led to believe. In moderately preterm-born infants (32-35 weeks' GA) hypoglycemia, defined as $<1.7 \mathrm{mmol} / \mathrm{L}$ $(30 \mathrm{mg} / \mathrm{dL})$, was found to be associated with an increased risk of parent-reported developmental delay at four years [15]. In our study, only four out of the 16 infants with hypoglycemia had one of more measurements below 1.7 $\mathrm{mmol} / \mathrm{L}$, which suggests that in very preterm infants blood glucose concentrations between $1.7 \mathrm{mmol} / \mathrm{L}$ and $2.6 \mathrm{mmol} /$ $\mathrm{L}$ may also lead to impaired neurological functioning on Day 15. Our cohort was, however, not large enough to suggest that this cutoff level automatically requires more aggressive intervention. Much is still unknown on optimal glucose metabolism in extremely preterm infants [30].

The second strongest association we found was between the presence of PDA and impaired neurological functioning on Day 8. In contrast to our hypothesis, however, this association had disappeared on Day 15. Janz-Robinson et al. [31] reported that infants who were pharmaceutically treated for PDA have a higher risk of neurodevelopmental delay at the age of 2 to 3 years compared to a group who did not receive pharmaceutical treatment for PDA. Infants who required surgical closure of the PDA had the highest risk of neurodevelopmental delay [31]. Our data suggest that the negative effect of the presence of PDA on early neurological outcome could be reversed if the PDA closes after the 5 week, but before the end of the second week after birth. We did not record the day the PDA had closed. It would be interesting to see if the motor optimality score of the GMs improves after ductus closure. Further study is required.

As expected, we did not find any association between the duration of mechanical ventilation and neurological functioning on Day 8. On Day 15, however, the duration of mechanical ventilation was independently associated with impaired neurological functioning. It is an interesting finding that in our study, after merely 2 weeks, mechanical ventilation was already negatively associated with early neurological functioning. Previously, prolonged mechanical ventilation for more than 4 weeks and bronchopulmonary dysplasia (BPD), defined as requiring supplemental oxygen at the postmenstrual age of 36 weeks, were reported as risk factors for impaired neurodevelopment [32]. We suggest 
that infants with only 2 weeks of mechanical ventilation could also run a higher risk of impaired neurodevelopment, but may be less outspoken than in the case of infants who were mechanically ventilated for more than 4 weeks. We do not suggest that the association between mechanical ventilation and neurological outcome is necessarily causal. Further research is required to clarify this point.

The findings on GMA obtained during the first 2 weeks after birth may well reflect functional development later in life. There is a continuum of motor patterns from prenatal to early postnatal period. The GMA is of special interest, as they provide in their altered quality a most reliable indicator of brain function [33]. The quality of GMs from the second week after birth onwards is a strong predictor of motor disorders including cerebral palsy [18], minor neurological and motor disorders [21-23], and cognitive skills [20, 24]. Our findings indicate that the risk factors we studied may indeed alter neurological functioning later on. Whether GMOS indeed provides additional information beyond already known risk factors remains to be elucidated, for example by follow-up of this cohort up to school age. From earlier long-term followup studies of GMA in preterm infants [24, 34, 35], we expect that poor GMOS is predictive of minor neurological dysfunction and somewhat poorer cognition.

We recognize several limitations. The number of infants who participated was quite small and for logistic reasons (transfer to secondary level hospitals) we missed some video recordings. It was a single center study, but our study population can be considered as representing a tertiary referral center. The prevalence of sepsis was rather high in our group. On Day 8, seven (10\%) infants were scored hypokinetic due to sepsis, and we had to exclude these cases from the analyses because we could not calculate the GMOS. On Day 15, these seven infants and some others had recovered from sepsis, and their GMOS' could now be scored. This may have confounded our findings regarding the risk factors under study, because sepsis and inflammatory cytokines are one of the mechanisms of white matter injury [36]. A final limitation concerned the low prevalence of some of the risk factors. Hyperglycemia, for example, only occurred in three (4\%) infants. A larger study is needed to investigate whether hyperglycemia and other early clinical problems with a lower prevalence are associated with early neurological functioning.

A strong point of our study is related to our use of the GMOS. The detailed assessment of the GMs made it possible to document subtle characteristics in the infants' neurological functioning during the neonatal period. For example, poor repertoire GMs can look stiff and monotonous, or they might still have some variability, but just not enough to be scored as normal [37]. Had we only used global assessment of the GMs, these cases would all fall in the same category. Using this detailed, semi-quantitative approach, we were able to better document associations with risk factors and the infant's neurological functioning, than we would have been able to do with only the global assessment.

Our study may have clinical implications. We found an association between hypoglycemia, defined as blood glucose $<2.6 \mathrm{mmol} / \mathrm{L}$, during the first $48 \mathrm{~h}$ and impaired neurological functioning on Day 15. In our study population, $24 \%$ of the infants had a least one hypoglycemic episode and $15 \%$ had two or more episodes of hypoglycemia despite following the guidelines to prevent this. Our study suggests that not only hypoglycemia, but also the frequency of hypoglycemia is negatively associated with the early neurological outcome. This indicates that early, frequent glucose check-ups and treatment of hypoglycemia in preterm infants may be important to improve their neurodevelopmental outcomes. Another implication concerns the presence of a PDA. Almost $40 \%$ of the infants included in this study had a symptomatic PDA. In these cases, the quality of the GMs was significantly poorer on Day 8, but this association had disappeared on Day 15. It is important to confirm that this association with neurological functioning is indeed transient, and further research is required to determine if early neurological functioning is related to the moment of closure of PDA. A final implication concerns mechanical ventilation. We found an association between the duration of mechanical ventilation and poorer neurological functioning on Day 15. Physicians should, therefore, carefully consider the advantages and disadvantages of continuing mechanical vertilation in the individual infant.

In conclusion, our findings demonstrated that duration of mechanical ventilation and the frequency of hypoglycemic episodes during the first $48 \mathrm{~h}$ were associated with impaired neurological functioning on Day 15. Neonatologists should try to prevent hypoglycemic and hyperglycemic episodes, because of the risk they involve. The presence of PDA was associated with impaired neurological functioning on Day 8. Considering the predictive value of the quality of GMs for motor and cognitive skills at follow-up [19, 20,24, 28], our findings may enable the early identification of preterm individual infants at risk of impaired neurodevelopmental outcomes. Pediatricians should pay more attention to a reduced optimality of GMs, which identifies impaired neurological functioning in preterm infants. GMA until the age of three to 5 months may help to identify infants at risk of these problems.

Acknowledgements We greatly appreciate the help of Titia van Wulfften Palthe, PhD, for correcting the English manuscript.

\section{Compliance with ethical standards}

Conflict of interest The authors declare that they have no conflict of interest. 


\section{References}

1. Grisaru-Granovsky S, Reichman B, Lerner-Geva L, Boyko V, Hammerman C, Samueloff A, et al. Israel Neonatal Network. Population-based trends in mortality and neonatal morbidities among singleton, very preterm, very low birth weight infants over 16 years. Early Hum Dev. 2014;90:821-7.

2. Platt MJ, Cans C, Johnson A, Surman G, Topp M, Torrioli MG, et al. Trends in cerebral palsy among infants of very low birth weight $(<1500 \mathrm{~g})$ or born prematurely $(<32$ weeks $)$ in 16 European centres: a database study. Lancet. 2007;369:43-50.

3. Azria E, Kayem G, Langer B, Marchand-Martin L, Marret S, Fresson $\mathrm{J}$, et al. Neonatal mortality and long-term outcome of infants born between 27 and 32 weeks of gestational age in breech presentation: The EPIPAGE cohort study. PLoS ONE. 2016;11: e0145768.

4. Serenius F, Ewald U, Farooqi A, Fellman V, Hafström M, Hellgren $\mathrm{K}$, et al. Neurodevelopmental outcomes among extremely preterm infants 6.5 years after active perinatal care in Sweden. JAMA Pediatr. 2016;170:954-63.

5. de Kieviet JF, Piek JP, Aarnoudse-Moens CS, Oosterlaan J. Motor development in very preterm and very low-birth-weight children from birth to adolescence: a meta-analysis. JAMA. 2009;302:2235-42.

6. Saigal S, Doyle LW. An overview of mortality and sequelae of preterm birth from infancy to adulthood. Lancet. 2008;371:75-84.

7. Laptook AR, O'Shea TM, Shankaran S, Bhaskar B. Adverse neurodevelopmental outcomes among extremely low birth weight infants with a normal head ultrasound: prevalence and antecedents. Pediatrics. 2005;115:673-80.

8. Skidmore MD, Rivers A, Hack M. Increased risk of cerebral palsy among very low-birth weight infants with chronic lung disease. Dev Med Child Neurol. 1990;32:325-32.

9. Sun H, Cheng R, Kang W, Xiong H, Zhou C, Zhang Y, et al. High-frequency oscillatory ventilation versus synchronized intermittent mandatory ventilation plus pressure support in preterm infants with severe respiratory distress syndrome. Respir Care. 2014;59:159-69.

10. Bourgoin L, Cipierre C, Hauet Q, Basset H, Gournay V, Rozé JC, et al. Neurodevelopmental outcome at 2 years of age according to patent ductus arteriosus management in very preterm infants. Neonatology. 2016;109:139-46.

11. Mitra S, Rønnestad A, Holmstrøm H. Management of patent ductus arteriosus in preterm infants--where do we stand? Congenit Heart Dis. 2013;8:500-12.

12. Boluyt N, van Kempen A, Offringa M. Neurodevelopment after neonatal hypoglycemia: a systematic review and design of an optimal future study. Pediatrics. 2006;117:2231-43.

13. Lucas A, Morley R, Cole TJ. Adverse neurodevelopmental outcome of moderate neonatal hypoglycaemia. BMJ. 1988;297:1304-8.

14. Tin W, Brunskill G, Kelly T, Fritz S. 15-year follow-up of recurrent "hypoglycemia" in preterm infants. Pediatrics. 2012;130:e1497-503.

15. Kerstjens JM, Bocca-Tjeertes IF, de Winter AF, Reijneveld SA, Bos AF. Neonatal morbidities and developmental delay in moderately preterm-born children. Pediatrics. 2012;130:e265-72.

16. Prechtl HF. Qualitative changes of spontaneous movements in fetus and preterm infants are a marker of neurological dysfunction. Early Hum Dev. 1990;23:151-8.

17. Spittle AJ, Doyle LW, Boyd RN. A systematic review of the clinimetric properties of neuromotor assessments for preterm infants during the first year of life. Dev Med Child Neurol. 2008;50:254-66.

18. Prechtl HFR, Einspieler C, Cioni G, Bos AF, Ferrari F, Sontheimer D. An early marker for developing neurological deficits after perinatal brain lesions. Lancet. 1997;349:1361-3.
19. Einspieler C, Prechtl HF. Prechtl's assessment of general movements: a diagnostic tool for the functional assessment of the young nervous system. Ment Retard Dev Disabil Res Rev. 2005; 11:61-7.

20. Einspieler C, Bos AF, Libertus ME, Marschik PB. The general movement assessment helps us to identify preterm infants at risk for cognitive dysfunction. Front Psychol. 2016;7:406.

21. Tanis JC, Schmitz DM, Boelen MR, Casarella L, van den Berg PP, Bilardo CM, et al. General movements after fetal growth restriction in relation to prenatal Doppler flow patterns. Ultrasound Obstet Gynecol. 2016;48:772-8.

22. de Vries NK, Erwich JJ, Bos AF. General movements in the first fourteen days of life in extremely low birth weight (ELBW) infants. Early Hum Dev. 2008;84:763-8.

23. de Vries NK, van der Veere CN, Reijneveld SA, Bos AF. Early neurological outcome of young infants exposed to selective serotonin reuptake inhibitors during pregnancy: results from the observational SMOK study. PLoS ONE. 2013;8:e64654.

24. Bruggink JL, Van Braeckel KN, Bos AF. The early motor repertoire of children born preterm is associated with intelligence at school age. Pediatrics. 2010;125:e1356-63.

25. Einspieler C, Marschik PB, Pansy J, Scheuchenegger A, Krieber $\mathrm{M}$, Yang $\mathrm{H}$, et al. The general movement optimality score: a detailed assessment of general movements during preterm and term age. Dev Med Child Neurol. 2016;58:361-8.

26. Ploegstra WM, Bos AF, de Vries NK. General movements in healthy full term infants during the first week after birth. Early Hum Dev. 2014;90:55-60.

27. Verhagen EA, Van Braeckel KN, van der Veere CN, Groen H, Dijk PH, Hulzebos CV, et al. Cerebral oxygenation is associated with neurodevelopmental outcome of preterm children at age 2 to 3 years. Dev Med Child Neurol. 2015;57:449-55.

28. Ferrari F, Cioni G, Prechtl HF. Qualitative changes of general movements in preterm infants with brain lesions. Early Hum Dev. 1990;23:193-231.

29. Kloosterman GJ. On intrauterine growth: the significance of prenatal care. Int J Gynaecol Obstet. 1970;8:895-912.

30. Thompson-Branch A, Havranek T. Neonatal hypoglycemia. Pediatr Rev. 2017;38:147-57.

31. Janz-Robinson EM, Badawi N, Walker K, Bajuk B, Abdel-Latif ME. Neonatal intensive care units network. Neurodevelopmental outcomes of premature infants treated for patent ductus arteriosus: a population-based cohort study. J Pediatr. 2015;167:1025-32.

32. Walsh MC, Morris BH, Wrage LA, Vohr BR, Poole WK, Tyson $\mathrm{JE}$, et al. Extremely low birth weight neonates with protracted ventilation: mortality and 18-month neurodevelopmental outcomes. J Pediatr. 2005;146:798-804.

33. Einspieler C, Marschik PB, Prechtl HFR. Human motor behavior. Prenat Orig Early Post Dev J Psychol. 2008;216:148-54.

34. Bruggink JLM, van Spronsen FJ, Wijnberg-Williams BJ, Bos AF. Pilot use of the early motor repertoire in infants with inborn errors of metabolism: outcomes in early and middle childhood. Early Hum Dev. 2009;85:461-5.

35. Bruggink JLM, Einspieler C, Butcher PR, van Braeckel KNJA, Prechtl HFR, Bos AF. The quality of the early motor repertoire in preterm infants predicts minor neurological dysfunction at school age. J Pediatr. 2008;153:32-9.

36. Procianoy RS, Silveira RC. Association between high cytokine levels with white matter injury in preterm infants with sepsis. Pediatr Crit Care Med. 2012;13:183-7.

37. Nakajima Y, Einspieler C, Marschik PB, Bos AF, Prechtl HF. Does a detailed assessment of poor repertoire general movements help to identify those infants who will develop normally? Early Hum Dev. 2006;82:53-9. 